\title{
Finite Element Modelling Tuned on Experimental Testing for the Structural Health Assessment of an Ancient Masonry Arch Bridge
}

\author{
G. Castellazzi, S. De Miranda, and C. Mazzotti \\ DICAM Department, University of Bologna, Viale Risorgimento 2, 40136 Bologna, Italy \\ Correspondence should be addressed to G. Castellazzi, giovanni.castellazzi@unibo.it
}

Received 22 August 2012; Accepted 30 August 2012

Academic Editor: Ivan Bartoli

Copyright (c) 2012 G. Castellazzi et al. This is an open access article distributed under the Creative Commons Attribution License, which permits unrestricted use, distribution, and reproduction in any medium, provided the original work is properly cited.

This paper presents the structural health assessment of a railway ancient masonry arch bridge located in Bologna, Italy. A three-dimensional finite element model of the entire bridge, tuned on in situ experimental tests, has been used for the assessment. In particular, the finite element model has been employed to evaluate the structural health of the bridge both in its actual state and in the hypothesis of a structural strengthening intervention.

\section{Introduction}

The train loads and the train traffic amount increased tremendously in this last century. Nevertheless, many railway masonry arch bridges built in the nineteenth and twentieth centuries are still in service. For this reason and due to the continuous exposure to environmental aggressive conditions, a good number of these bridges suffer important mechanical deteriorations. The definition of an effective process of assessment of the actual structural health of these fundamental infrastructures is thus becoming more and more important (see, e.g., [1-5] and the references therein).

In the present paper, the procedure applied for the structural health assessment of the railway masonry arch bridge crossing the Reno river in Bologna (Italy), see Figure 1, is presented, together with the obtained results. Some preliminary results have been presented in [6]. The procedure is based on the combined use of three-dimensional finite element modelling [7-10] and in situ experimental testing. A number of experimental tests have been carried out in order to find out both the material properties of the masonry constituting the arches and the piers and the structural behavior of the bridge or of portions of it. In particular, accurate static and dynamic load tests have been performed on some arches whereas simplified dynamic tests have been repeated on all the spans of the bridge in order 


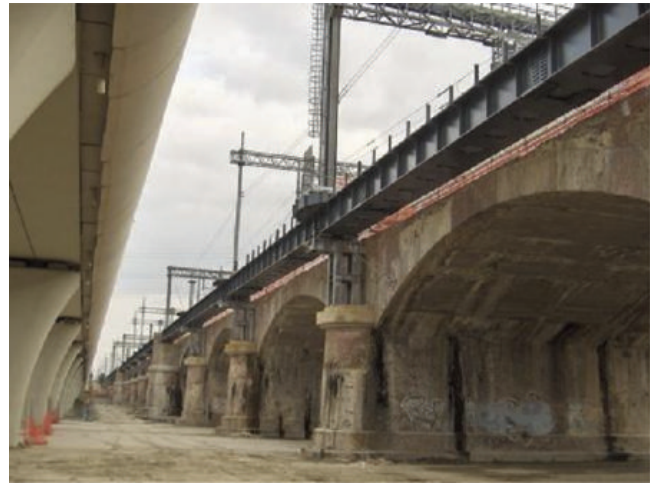

(a)

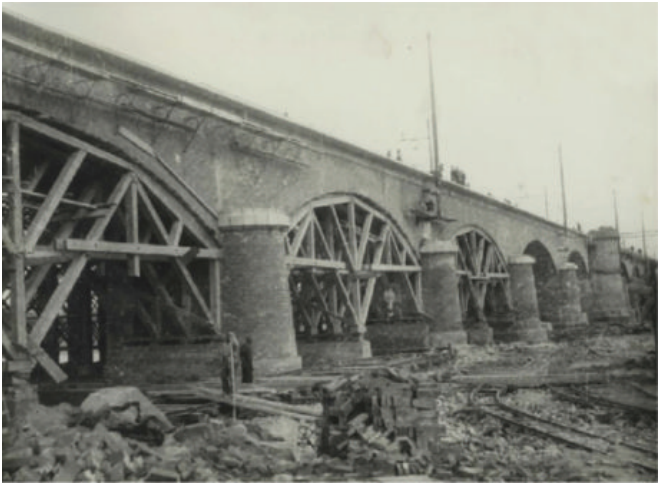

(b)

Figure 1: (a) Longitudinal view of the multi-span masonry arch bridge as appears today and (b) view of a construction phase, presumably dated around 1852.

to verify the homogeneity of their structural behavior. The experimental findings have been used to tune a three-dimensional finite element model of the whole bridge, able to describe the static and dynamic behavior of the structure under service conditions (train traffic). In particular, a part of the experimental outcomes have been used to calibrate the finite element model and a part to validate it. A very good agreement between experimental and numerical results has been obtained, so confirming the accuracy of the assumptions made in setting up the finite element model. Then, the tuned finite element model has been used for the evaluation of the structural health of the bridge both in its actual state and in the hypothesis of a structural strengthening intervention.

The paper is organized as follows. The three-dimensional finite element model is presented in Section 2. Section 3 is devoted to the description of the in situ experimental tests. The tuning of the finite element model is presented in Section 4 and its use for the structural health assessment of the bridge in Section 5. Some concluding remarks end the paper (Section 6).

\section{The Three-Dimensional Finite Element Model}

The bridge, built in 1852, has 15 arch spans and an overall length of $360 \mathrm{~m}$. Arches have a $20 \mathrm{~m}$ free span, and piers are $2 \mathrm{~m}$ thick and $10 \mathrm{~m}$ high (Figure 2). The bridge was originally designed for two railway tracks, with a barrel width of $9 \mathrm{~m}$ (older part/bridge in the following). Later, the bridge was enlarged building a second, $6 \mathrm{~m}$ width, barrel (newer part/bridge in the following) in order to increase the number of tracks (Figure 2). Visual inspection of the intrados reveals that the barrels seem to be separated (percolation from the rail deck is visible along all the arches), so slips between the two parts are possible. The evaluation of the degree of collaboration of the two parts is one of the key aspects of the investigation.

A three-dimensional finite element model of the whole bridge, able to describe its static and dynamic behaviors, has been set up (Figure 3). The model, developed using the commercial code Abaqus [11], has been defined starting from the existing historical drawings and encompasses details discovered during the on-site inspection. Fine description of all the geometry's components is given (Figure 4) along with the subdivision of material 


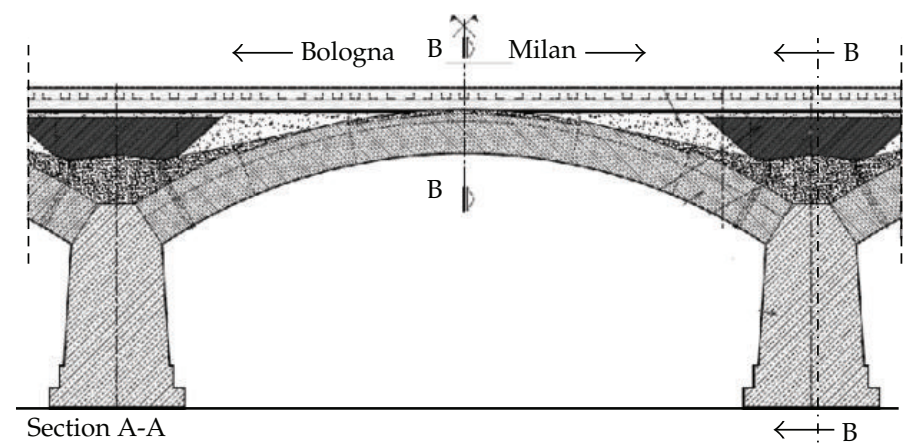

(a)

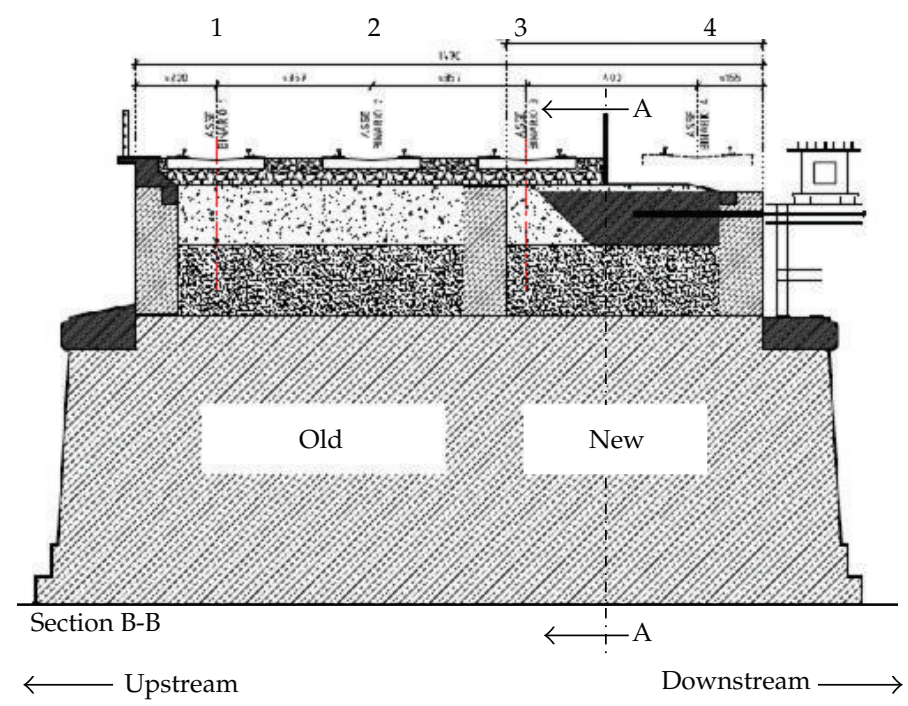

(b)

Figure 2: (a) Longitudinal and (b) transverse cross sections of the typical bridge span with indication of different materials.

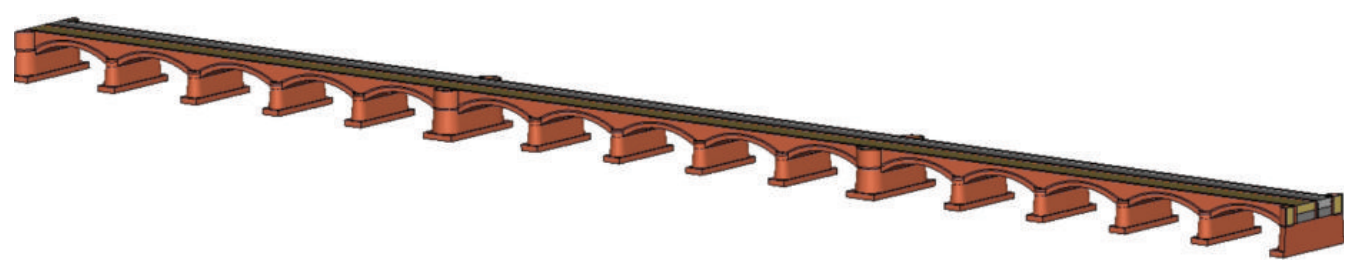

Figure 3: Full view of the 3D finite element model.

layers: masonry, filling material, and so on (Figure 5). Hexahedral 8-node linear elements (Abaqus C3D8) [11] have been employed together with the reduction to 6-node linear triangular prism elements (Abaqus C3D6) and the 4-node linear tetrahedral element (Abaqus C3D4). These elements are general purpose linear brick elements, fully integrated $(2 \times 2 \times 2$ integration points) and sensitive to extreme mesh distortions [12], which tend to give stiffer dynamic response for coarse meshes. Being the model intended to assess the structural health under service conditions, all materials have been assumed to work in the linear range thus 


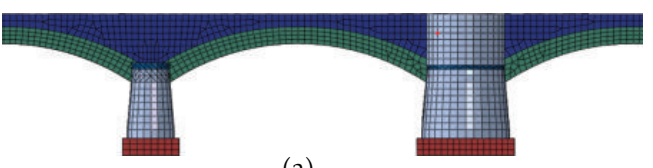

(a)

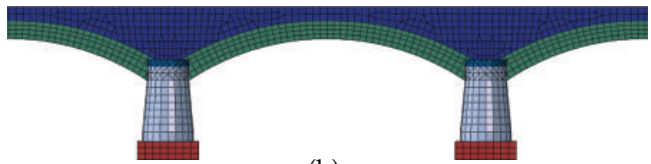

(b)

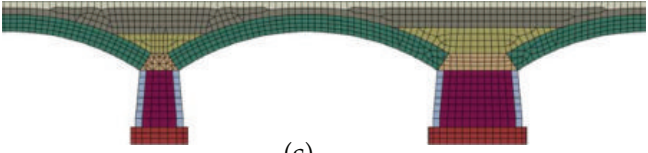

(c)

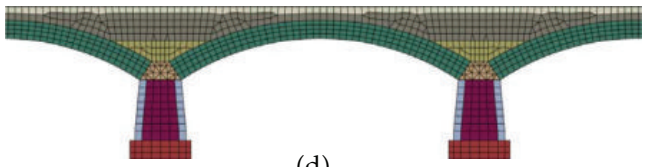

(d)

Figure 4: Partial views and sections of the 3D finite element model: representation of material properties subdivision.

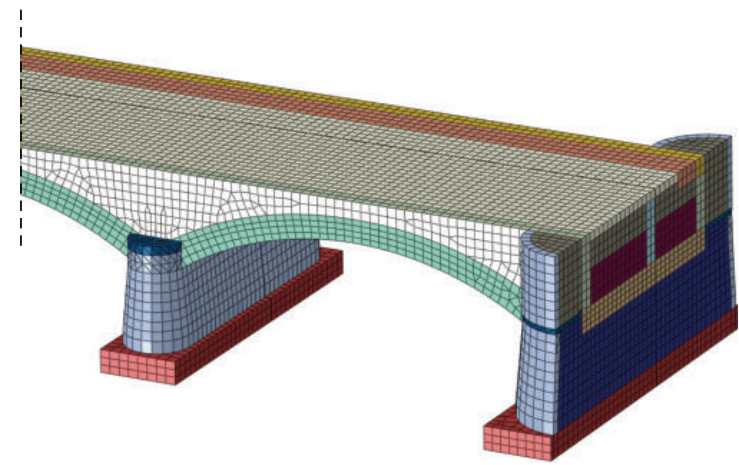

(a)

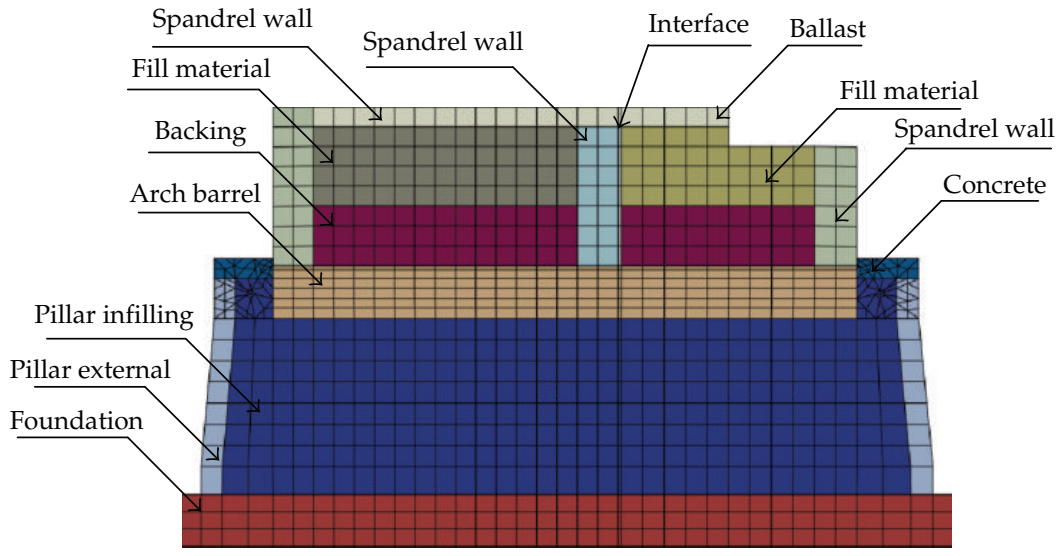

(b)

Figure 5: (a) View of a portion of the 3D finite element model of the structure with the representation of material properties subdivision and (b) section view using a cutting plane on the principal pillar.

producing a linear elastic model. Moreover, the materials have been assumed isotropic except for the material used to model the interface connecting the old bridge and the new bridge. This part has been modeled using an orthotropic material: in-plane directions are weak directions (sliding with friction), and the orthogonal direction to this plane possesses full stiffness as the masonry material (contact). Perfectly clamped boundary conditions at the base of the piles and at the abutments have been assumed. 


\section{In Situ Dynamic and Static Tests}

In this section, the dynamic and static tests carried out to investigate the structural behavior of the railway bridge under service loading are described. Loads generated by trains have been used in both cases.

\subsection{Dynamic Tests}

The purpose of dynamic tests is to identify the main natural frequencies and the mode shapes of the bridge. After verifying that all the spans of the bridge have a similar dynamic behavior (by means of simplified dynamic tests not reported here), a comprehensive dynamic test has been carried on a single span only (the 4th span, hereinafter called C4). The structure has been dynamically excited by means of the regular transit of trains.

\subsubsection{Instrumentation}

To measure the acceleration produced by the riding of the train on the bridge, twelve piezoelectric accelerometers have been used. They have a sensitivity of $10 \mathrm{~V} / \mathrm{g}$ and they have been placed at the arch intrados at midspan and at quarters of the arch freespan; six accelerometers measure the accelerations of the older part of the arch span while the other six measure the accelerations of the newer part (Figure 6(a)). All instruments have been mechanically clamped to the bridge in a direction orthogonal to the arch intrados (Figure 6(b)). Data have been acquired by using a 16-bit DAQ board and stored in a PC for further processing.

\subsubsection{Measurements and Dynamic Identification}

During the transit of trains on the bridge a number of acceleration time histories have been recorded. Figure 7(a) shows an example of time history recorded by accelerometer A7 (see Figure 6(a)) during a high velocity train transit. From the acceleration, power spectral density has been evaluated for each position and time history; an example of PSD corresponding to the acceleration of Figure 7(a) is reported in Figure 7(b).

Since the dynamic excitation applied to the bridge by the train during the riding is unknown, in order to identify the natural frequencies and mode shapes of the arch bridge an output-only identification technique has to be used. In particular, the Enhanced Frequency Domain Decomposition (EFDD) technique is applied at the present case [13]. It considers the dynamic force generated by the train like a white noise, and the PSD matrix of the problem is decomposed in order to obtain, starting from an n-DoF dynamic system, an n-SDoF systems. The PSD of the obtained systems is identified by classical SDoF techniques (peak picking) see [14] for further details. The first four natural frequencies identified are $f_{1}=9.12 \mathrm{~Hz}$, $f_{2}=9.62 \mathrm{~Hz}, f_{3}=11.21 \mathrm{~Hz}$, and $f_{4}=14.10 \mathrm{~Hz}$. The corresponding mode shapes are reported in Figure 8. The first two modes are both mainly flexural modes, but in the first case the older arch is more deflected than the newer one, confirming possible slips between arches. The opposite happens for the second mode shape. The third mode (Figure 8(c)) describes the deflection of the two arches with opposite signs, and also an appreciable torsional behavior can be found. Finally, the fourth mode (Figure $8(d)$ ) is similar to a beam second flexural mode with almost null deflection at midspan for both arches. 


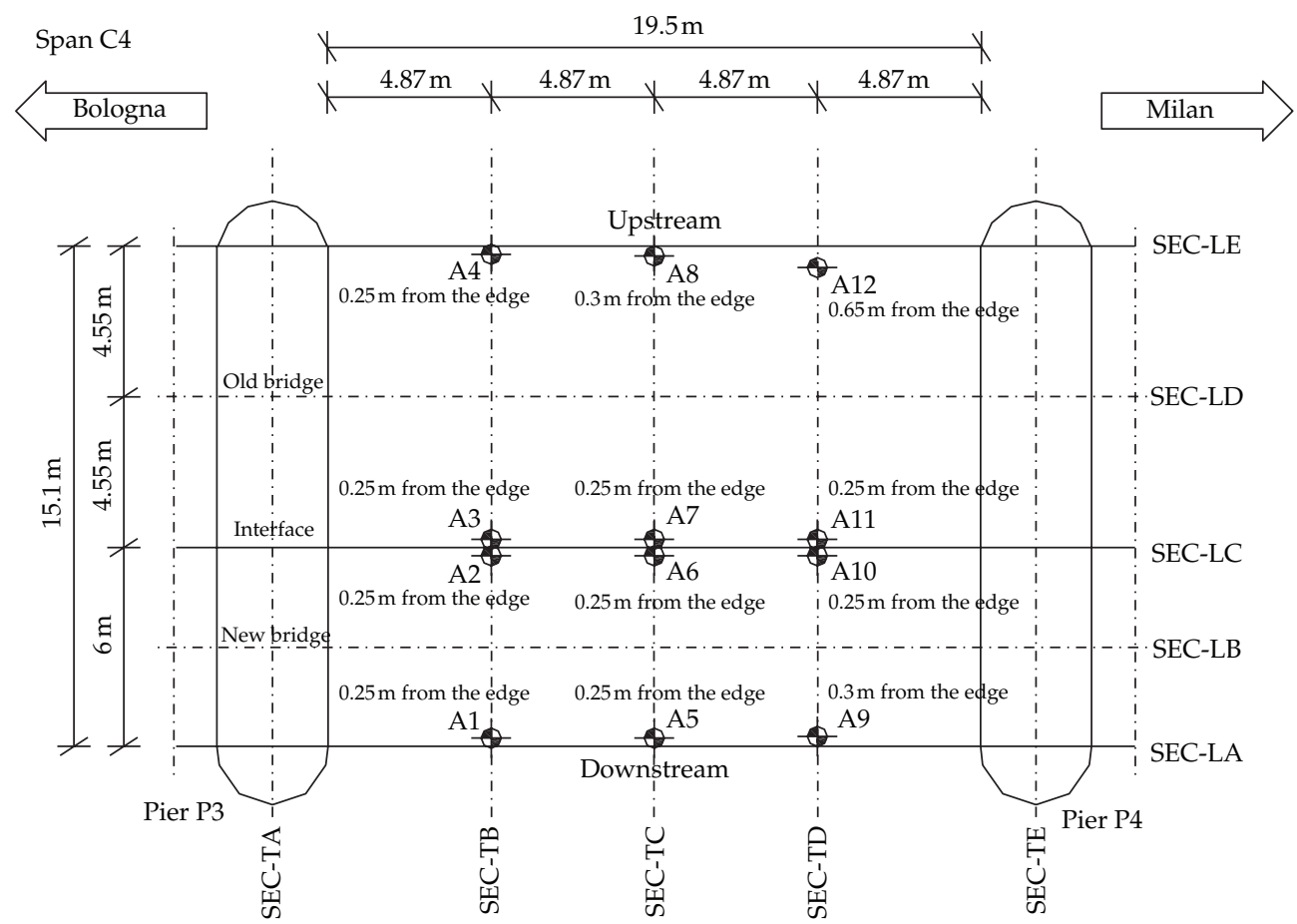

(a)

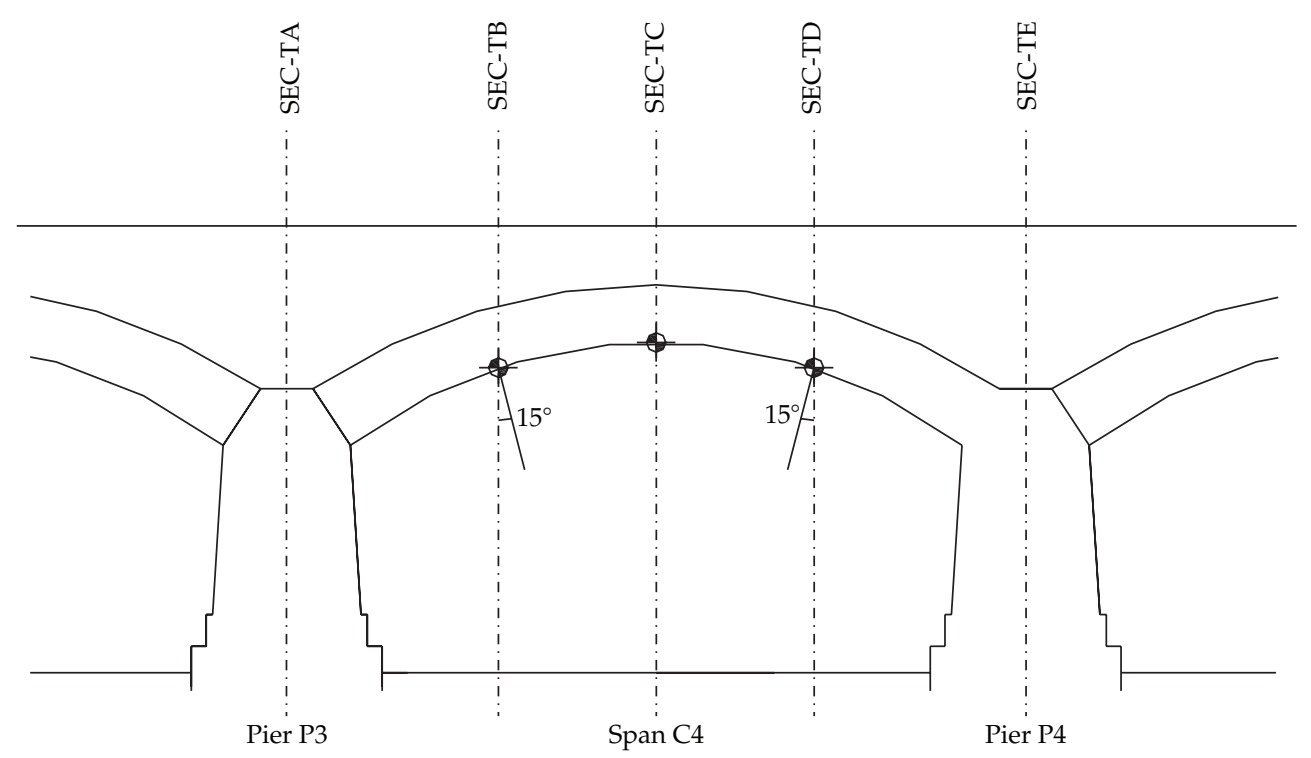

(b)

Figure 6: (a) Plan and (b) lateral view of the 4th span (C4) of the arch bridge with positions of accelerometers. 


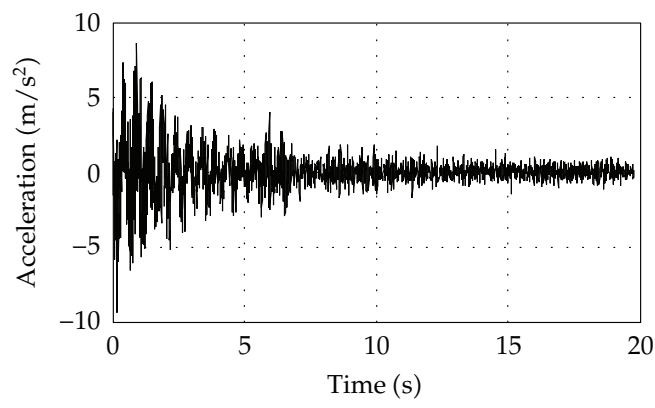

(a)

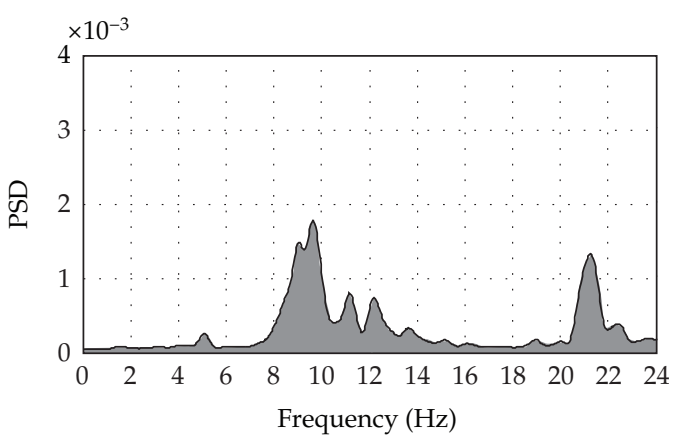

(b)

Figure 7: (a) Example of acceleration recorded during the pas-sage of a train on the bridge and (b) corresponding power spectral density.

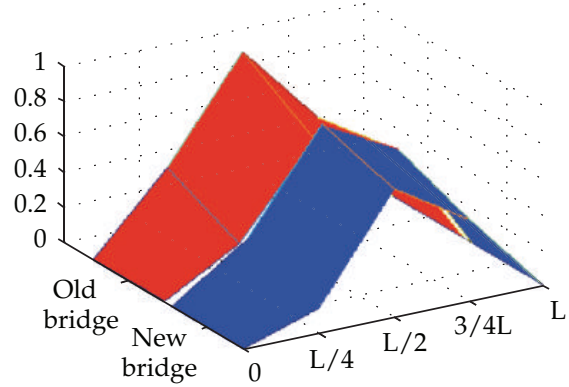

(a)

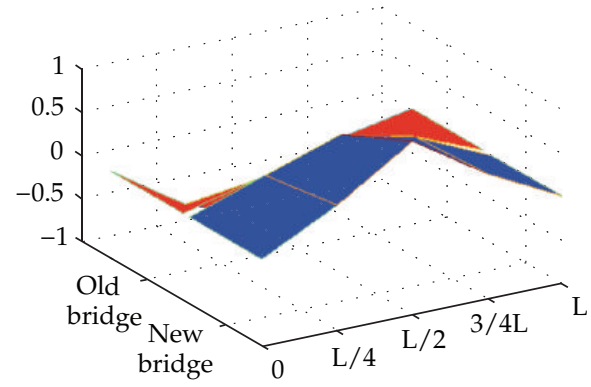

(c)

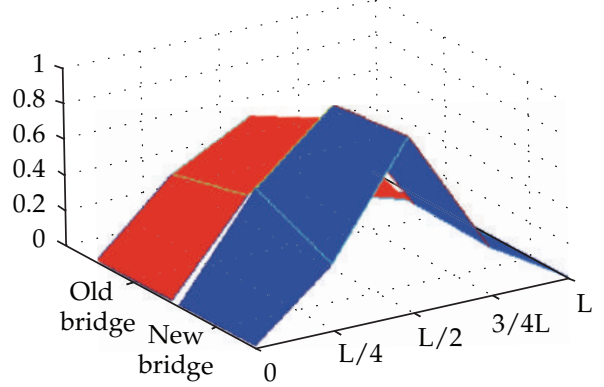

(b)

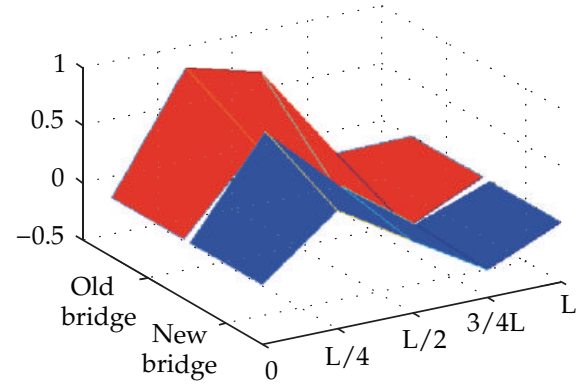

(d)

Figure 8: (a) Modal shapes of one arch span identified from dynamic tests.

\subsection{Static Test}

The same bridge span (C4) as before has been also tested under static loads. In particular, three locomotives have been used to apply the desired load combinations. In this way, a better investigation of the possible slips between the two arches (older and newer) has been performed.

\subsubsection{Instrumentation}

Vertical displacements of the arches intrados during the test have been measured by using nine LVDT displacement transducers (L1-L7 and F1-F2 of Figure 9(a)). They have been 


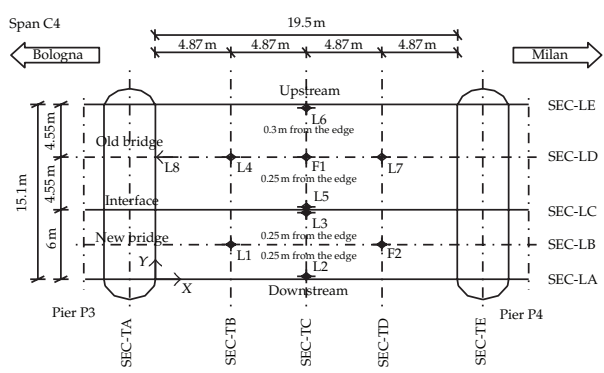

(a)

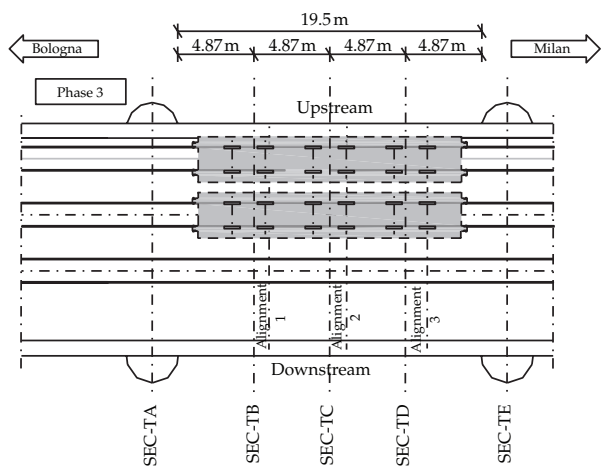

(c)

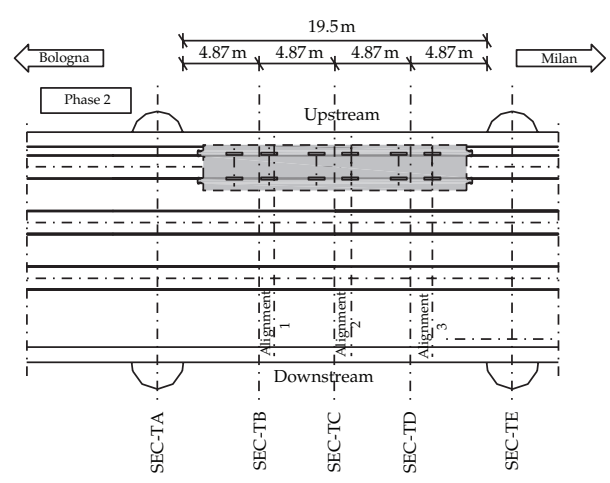

(b)

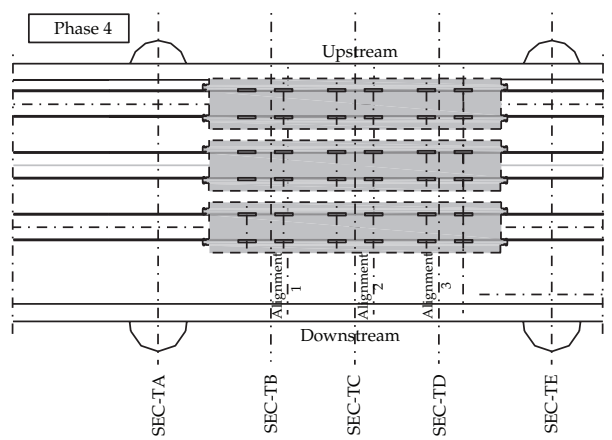

(d)

Figure 9: (a) Plan of the 4th span (C4) of the arch bridge with positions of displacement transducers and $(\mathrm{b}-\mathrm{d})$ phases 2 to 4 of static loadings.

positioned at midspan and at quarter-span of the arches. The vertical displacement of the piers is considered very small, and, consequently, they have been neglected.

\subsubsection{Load Combinations and Measurement}

The three available locomotives have been positioned in a number of different load combinations on the considered bridge span. In this way, it has been possible to investigate not only the overall flexural behavior but also the torsional effects and the degree of mechanical coupling between the two adjacent arches built in following periods. Locomotives positioned along tracks 1 and 2 weighted $106 \mathrm{t}$ while the third locomotive, moving on track 3 , weighted $120 \mathrm{t}$.

For the sake of brevity, only a part of the load combinations realized are shown in the paper. In particular, the torsional behavior has been investigated by placing one to three locomotives at midspan along tracks one to three (Figures 9(b), 9(c), and 9(d)). Figure 10(a) shows the corresponding results in terms of vertical displacements: an appreciable slip between the two arches can be observed even though their cross-sections remain substantially plane. In phase 4 the torsional rotation is smaller because of the position of track 3 , crossing the two arches. The flexural deflection of arches has been studied by positioning the three locomotives along tracks 1 to 3 progressively closer to midspan (see phases 6, 7, and 4 described resp. in Figures 11(a), 11(b), and 9(c)). The corresponding vertical displacements 


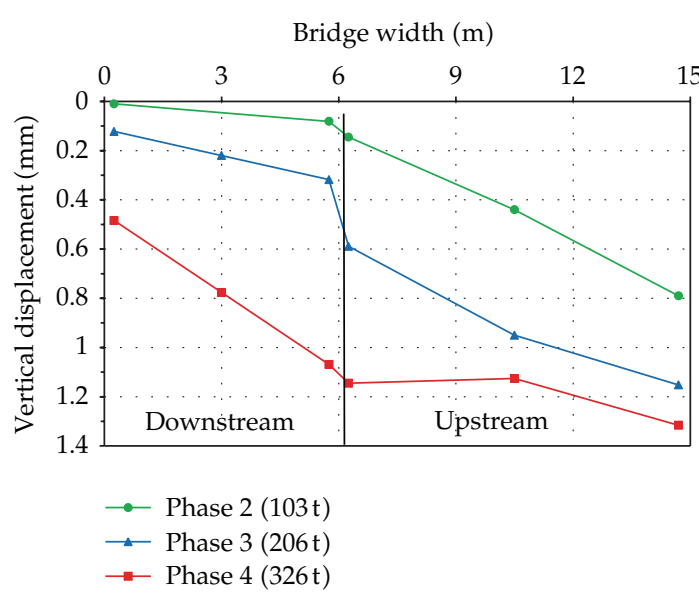

(a)

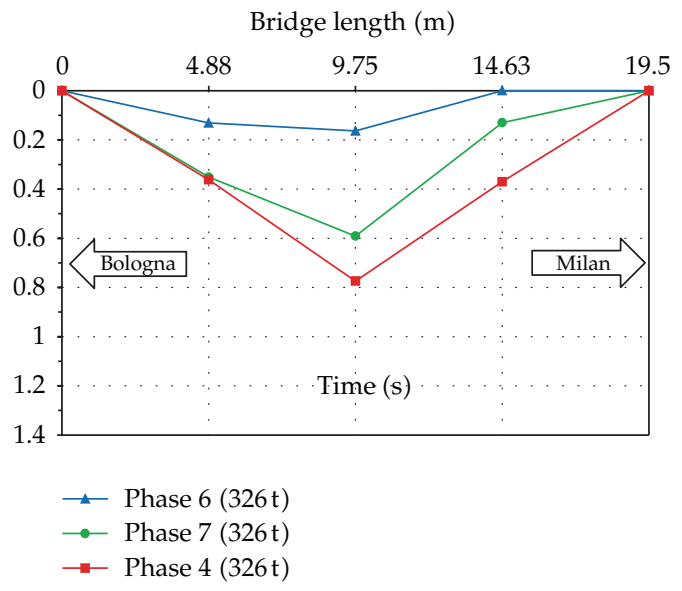

(b)

Figure 10: (a) Vertical displacement of midspan cross-section during loading phases 2-4; (b) vertical displacements along the longitudinal axis of the newer part of the instrumented arch-span during loading phases 6,7 , and 4 .

along the longitudinal axis of the newer arch (Figure 10(b)), as expected, show a deflected shape moving from the left pier (phase 6) toward midspan (phase 4). Finally, another loading condition (phase 12) has been applied to the bridge span, where the three locomotives were placed along the tracks shifted one with respect to the other ones (Figure 12). In this way the torsional effect has been applied not only at midspan but also along the whole span. Obtained results are shown later compared to numerical results.

\subsection{Material Characterization}

Together with the structural identification, the mechanical properties of masonry constituting the arch bridge have been also investigated [15]. Portions of masonry have been taken from five bridge spans (Figure 13(a)) in order to obtain several brick and mortar specimens. After proper geometrical regularization, brick specimens have been subjected to compression test while mortar specimens to double punching shear test (Figure 13(b)). Following procedure suggested in Eurocode 6 [16], from the results of single materials the masonry characteristic compressive strength $f_{m k}=8.2 \mathrm{MPa}$ has been obtained.

\section{Tuning of the Finite Element Model}

Usually, when experimental measurements are performed to validate numerical models, they do not coincide with the expected numerical results. These discrepancies originate from the uncertainties in simplifying assumptions of structural geometry, materials, as well as inaccurate boundary conditions. In the present case, most of the numerical simplification lies into the assumption of linear behavior for the materials. The problem of how to modify the numerical model taking into account the experimental results, essential for the reliability of the model, is known as model updating; see, for instance $[17,18]$.

Model updating procedure aims at minimizing the differences between the analytical and experimental results by changing uncertainty parameters such as material properties and 


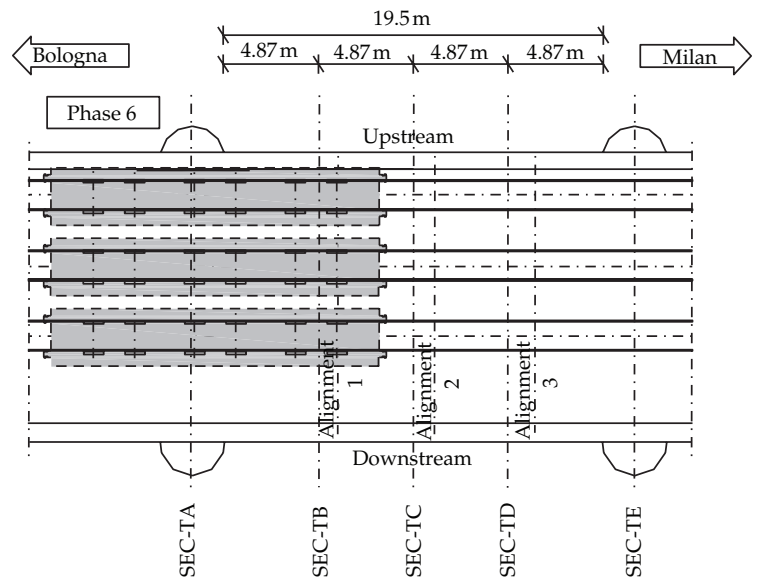

(a)

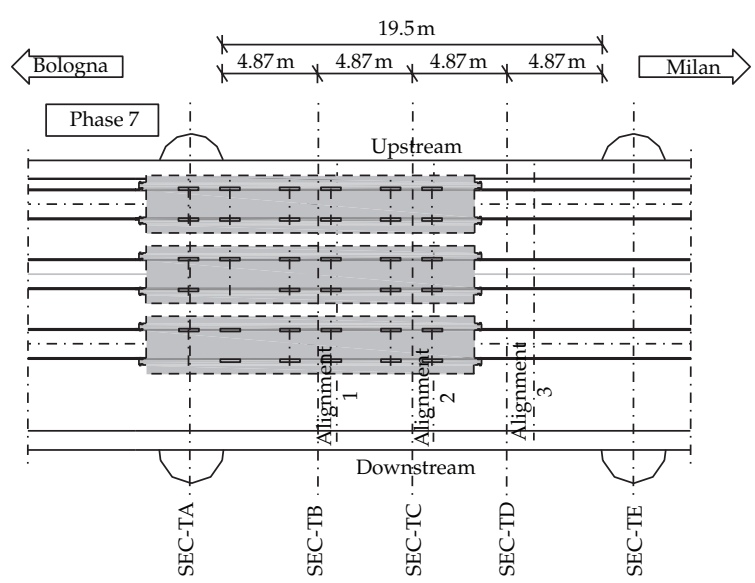

(b)

Figure 11: Phases (a) 6 and (b) 7 of static loadings.

boundary conditions. The model updating process typically consists of tuning some variables by using optimization algorithms and then automatic model updating using specialized software. Alternatively, manual tuning involves manual changes of the model geometry and modeling parameters by trial and error, guided by engineering judgment. Only manual tuning has been considered here since the model is linear elastic, and only few parameters have been tuned.

In order to apply this procedure, the structure has been subdivided into two substructures: one acting as main structure and the other acting as secondary structure useful only to distribute and transmit external loads to the main structure. Arches, stacks, abutments, and infilling of the piers (made of good-quality concrete) have been considered as structural parts (see Figure 5 for the different parts of the geometric model considered).

\subsection{The Masonry}

Mechanical properties of structural masonry have been evaluated by means of experimental tests (see Section 3.3). Therefore, during the model tuning, the values obtained in the above 


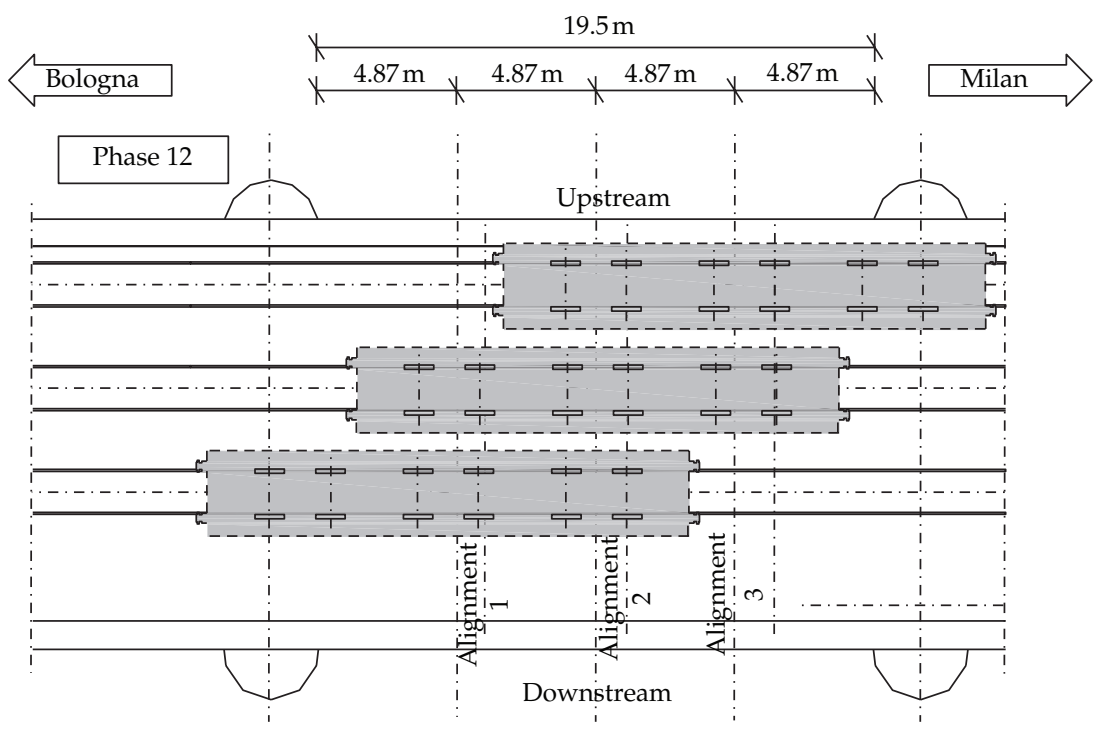

Figure 12: Phase 12 of static loading.

Table 1: Material properties.

\begin{tabular}{lccc}
\hline Material & Young's modulus (MPa) & Poisson's ratio & Density $\left(\mathrm{kg} / \mathrm{m}^{3}\right)$ \\
\hline \multirow{4}{*}{ Concrete } & Structural parts & \\
Masonry & 30000 & 0.20 & 2400 \\
Pillar infilling & 8200 & 0.20 & 1800 \\
Abutment & 20000 & 0.20 & 2400 \\
\hline \multirow{3}{*}{ Infilling } & 8200 & 0.20 & 2200 \\
Ballast & 100 & Nonstructural parts & \\
Masonry & 100 & 0.20 & 1800 \\
& 820 & 0.20 & 2000 \\
& $E_{1}=8200$ & 0.20 & - \\
Interface & $E_{2}=820$ & - & - \\
& $E_{3}=820$ & - & - \\
& $G_{12}=50$ & - & - \\
\hline
\end{tabular}

tests have been used. In particular, a Young's modulus $E=1000 f_{m k}=8.2 \mathrm{GPa}$ has been assumed, as suggested by Italian standards [19] starting from the experimental value of its compressive strength [15]. Other properties such as Poisson ratio and density have been introduced in the model by using conventional values taken from the literature, as well as for other materials not tested during the in situ survey (Table 1).

\subsection{Model Calibration}

The model calibration has been then performed according to results obtained during the static load tests and, in particular, using the load phase 4 (see Figure 9). Material properties of 


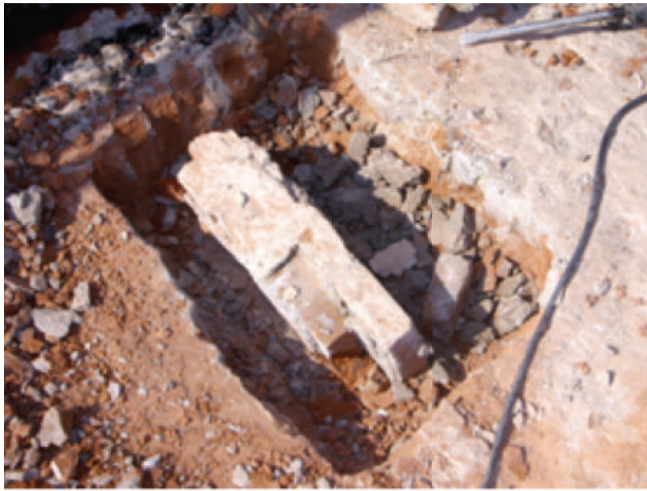

(a)

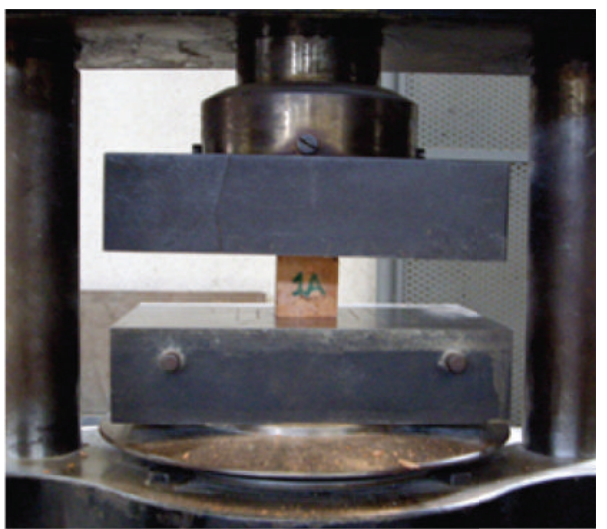

(c)

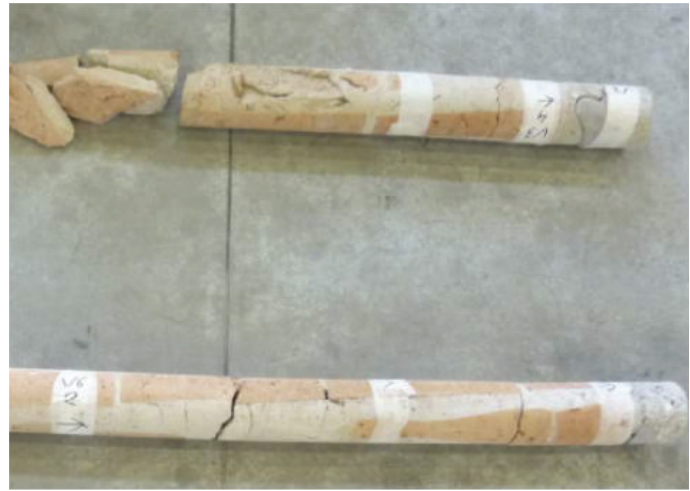

(b)

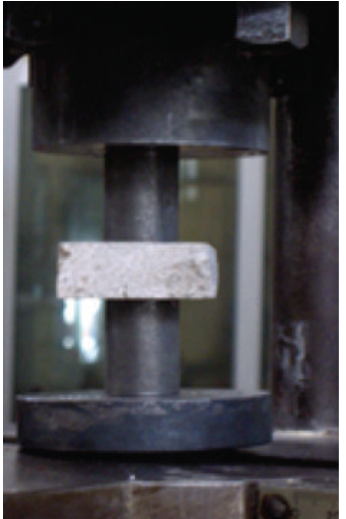

(d)

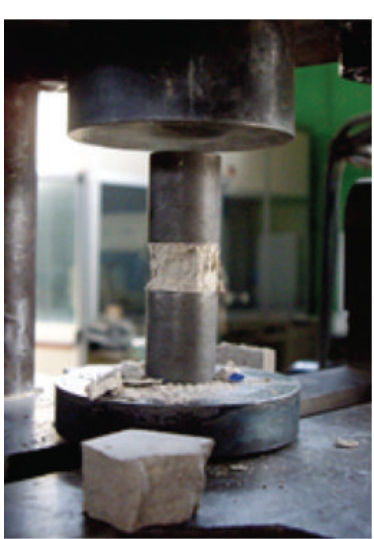

(e)

Figure 13: Sampling of a masonry portion from (a) the bridge arch barrel and from (b) the pillar; testing of (c) brick and (d)-(e) mortar specimens.

concrete and pillar infilling of the structural parts have been selected according to classical values from the literature (Table 1). Nonstructural parts have had the elasticity modulus selected according to their secondary role so that they cannot effectively contribute to the equilibrium of stresses produced by vertical loads. For this reason, the elasticity modulus has been chosen low enough to engender the quasielimination of tensile stresses in these parts; see Table 1. Moreover, as anticipated in Section 2, much attention has been posed in the modelling of the interface between the newer and older parts of the bridge. In particular, the interface has been modelled using an orthotropic material whose mechanical properties are collected in Table 1 where " 1 " denotes the direction orthogonal to the contact surface between the two parts of the bridge and " 2 " the vertical direction. The results provided by the updated model are reported in Figure 14(a), where the comparison of the computed and measured vertical deflections is shown at the instruments locations.

\subsection{Model Validation}

Results provided by the other static load phases have been used to verify the reliability of the numerical model once updated. For the sake of brevity, only two load phases are reported here: results corresponding to load phases 3 and 12 are reported in Figures 14(b) and 14(c), 

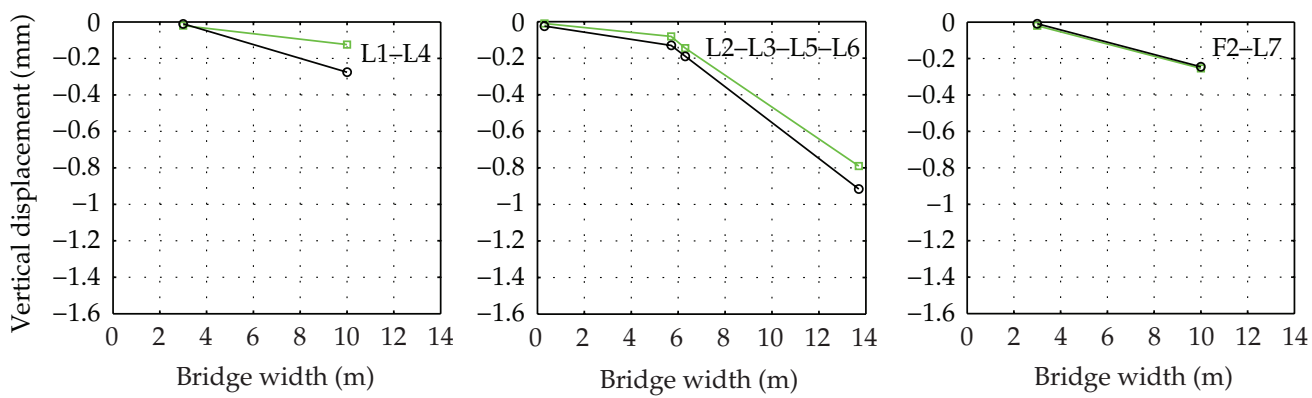

(a) Phase 4
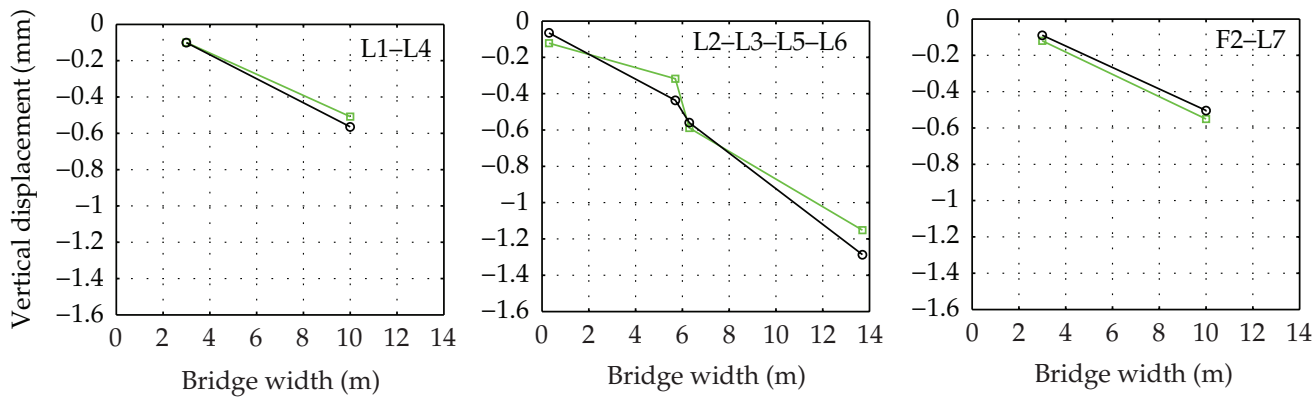

(b) Phase 3
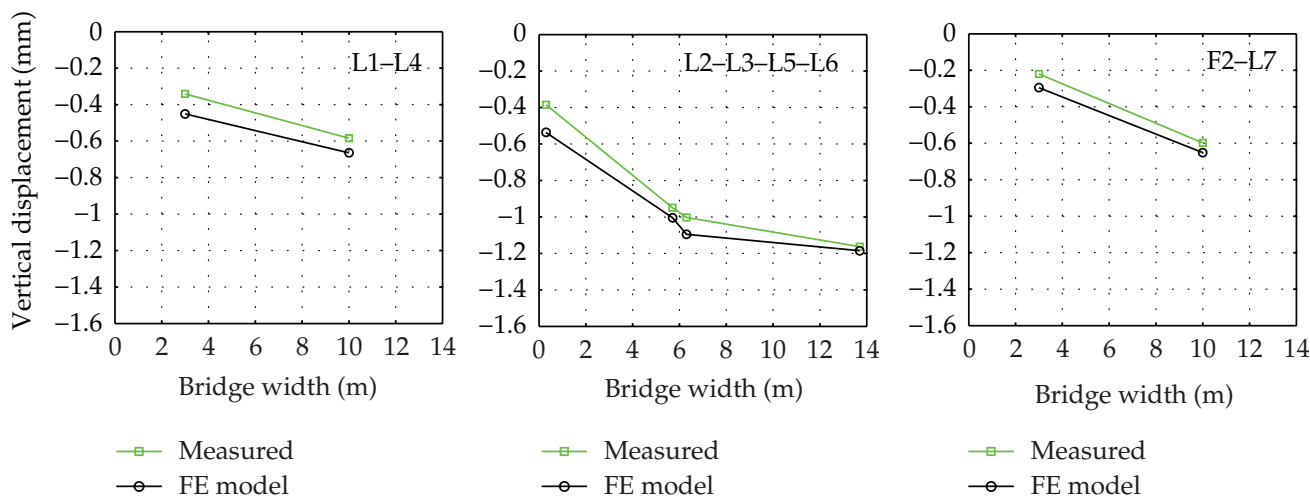

(c) Phase 12

Figure 14: Comparison of the computed and measured vertical deflections at the LVDT locations.

respectively. Comparison shows a very good agreement between the numerical results and the experimental findings.

Moreover, as for the dynamic behavior of the structure, a modal analysis has been performed on the three-dimensional finite element model previously used for the static analysis. Characterization of the structural masses has been done by means of the data provided by the in situ survey and using data from the literature. Block Lanczos mode extraction method has been used to solve the eigenvalue problem [11]. Seventy mode shapes have been extracted and considered for the comparison. The first and fourth computed mode shapes are reported in Figures 15(a) and 15(b), respectively, along with the corresponding mode shapes identified by the in situ dynamic tests. Figures refer to the same span (the 4th span, C4) where experimental tests have been carried out. 


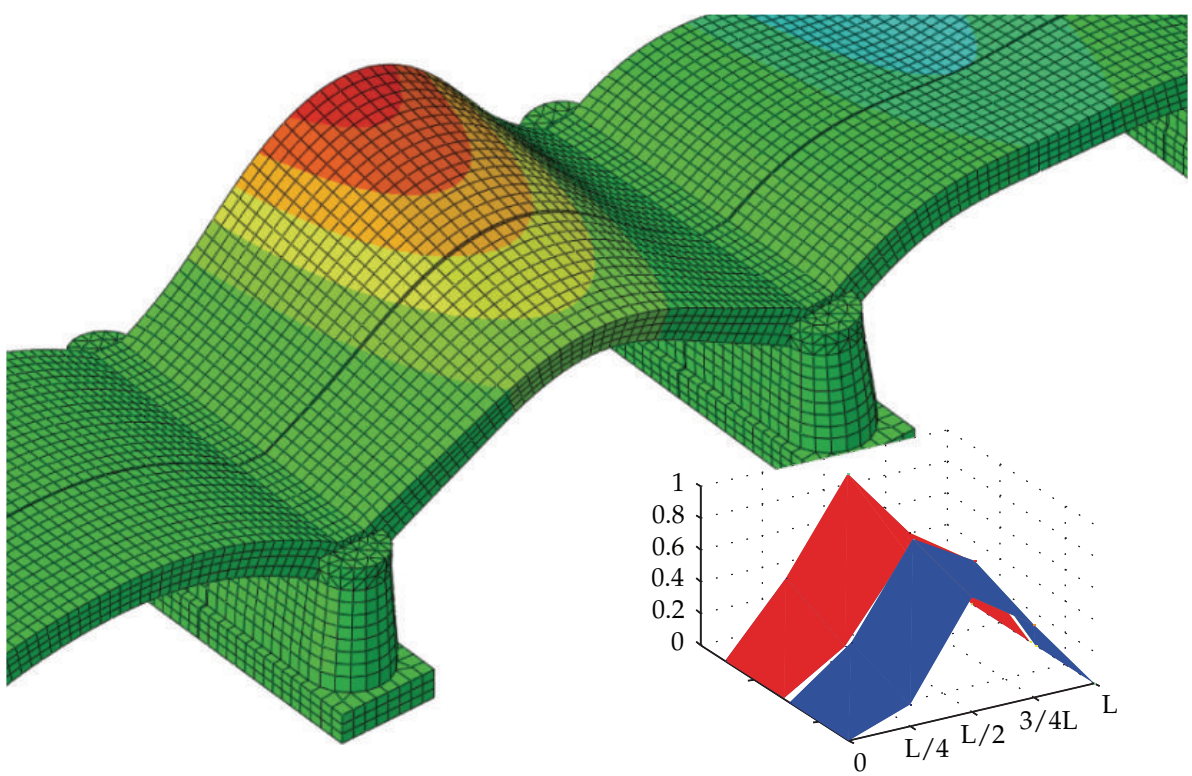

(a)

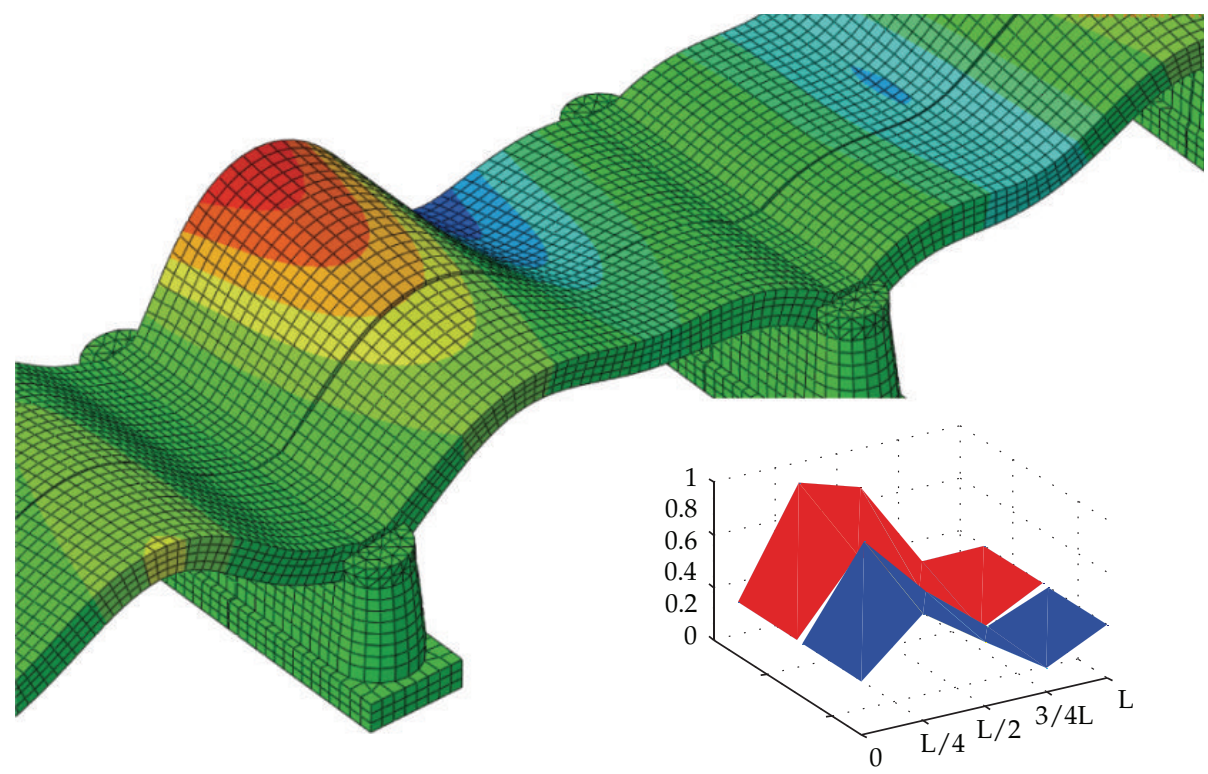

(b)

Figure 15: (a) First mode shape: freq $=9.35 \mathrm{~Hz}$ (numerical model), freq $=9.12 \mathrm{~Hz}$ (dynamic test); (b) Fourth mode shape: freq $=13.70 \mathrm{~Hz}$ (numerical model), freq $=14.1 \mathrm{~Hz}$ (dynamic test).

Colormap refers to the vertical displacement, as measured in situ. The numerical results are in very good agreement with the experimental ones although no model updating has been done on the structural masses.

The very good agreement between numerical and experimental results, obtained both in static and dynamic analyses, shows that the finite element model is reliable and could be employed to assess the structural health of the bridge. 


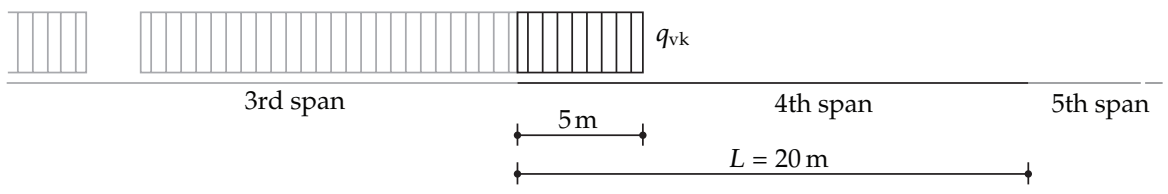

(a) Load case SW/2-1

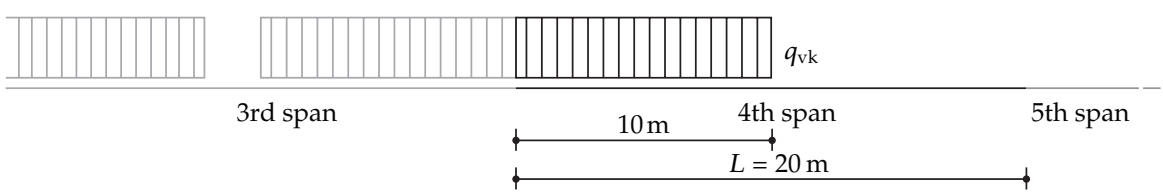

(b) Load case SW/2-2

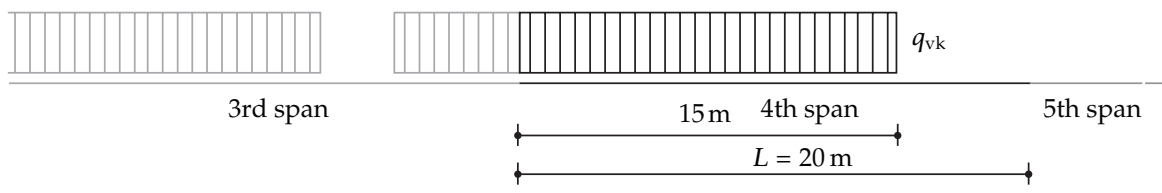

(c) Load case SW/2-3

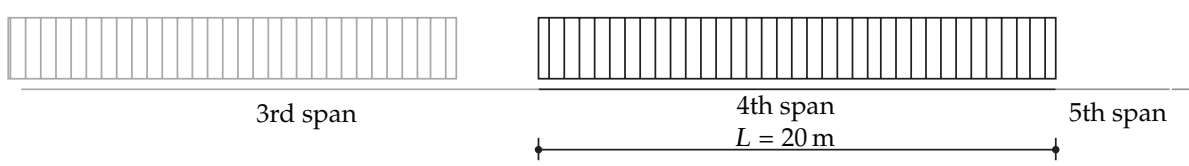

(d) Load case SW/2-4

Figure 16: Load cases according to SW $/ 2, q_{v k}=15 \mathrm{t} / \mathrm{m}$.

Table 2: Material properties of the lightweight concrete.

\begin{tabular}{lcc}
\hline Young's modulus $(\mathrm{MPa})$ & Poisson's ratio & Density $\left(\mathrm{kN} / \mathrm{m}^{3}\right)$ \\
\hline 23600 & 0.2 & 18
\end{tabular}

\section{Bridge Structural Health Assessment}

The finite element model described in the previous sections has been used to assess the structural health of the bridge both in its actual state and in the hypothesis of an intervention of structural strengthening. In particular, the strengthening intervention consists in the substitution of the actual fill material of the newer bridge (noncohesive) with lightweight concrete. The material properties for the lightweight concrete have been selected according to destructive experimental tests done on specimens; see Table 2. Indeed, the strengthening intervention is aimed at anchoring some tie rods to avoid the overturning of the spandrel wall. However, it can be interesting to evaluate its effect on the health of the whole structure.

The two railtracks on the newer part of the bridge (the part interested by the strengthening intervention, rails 3 and 4 in Figure 2) are loaded according to the load condition SW / 2 (see par-5.2.2.3.1.2 of [19]). This load condition schematically represents the static effects due to heavy trains. In particular, four load cases are considered, corresponding to various phases of the passage of the trains on the 4th span; see Figure 16. Maximum values of the stress for the different load cases and for both the bridge in the actual state and in the hypothesis of the structural strengthening are collected in Table 3. Moreover, with reference to 


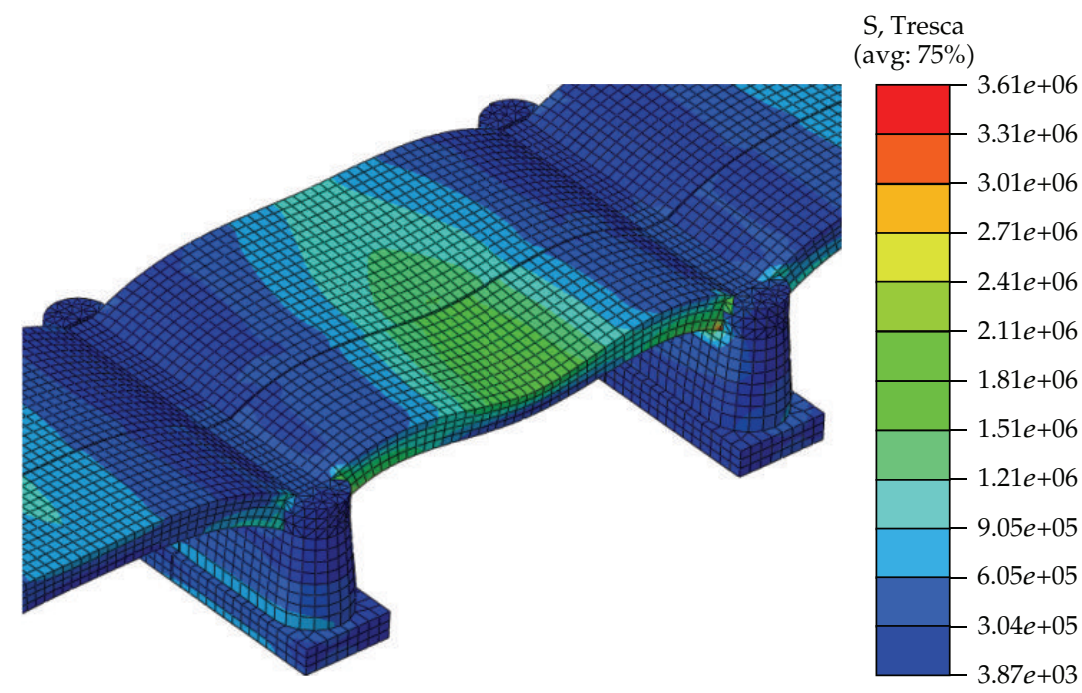

Figure 17: Resulting Tresca stress due to the load case SW/2-4 applied considering the actual state of the bridge.

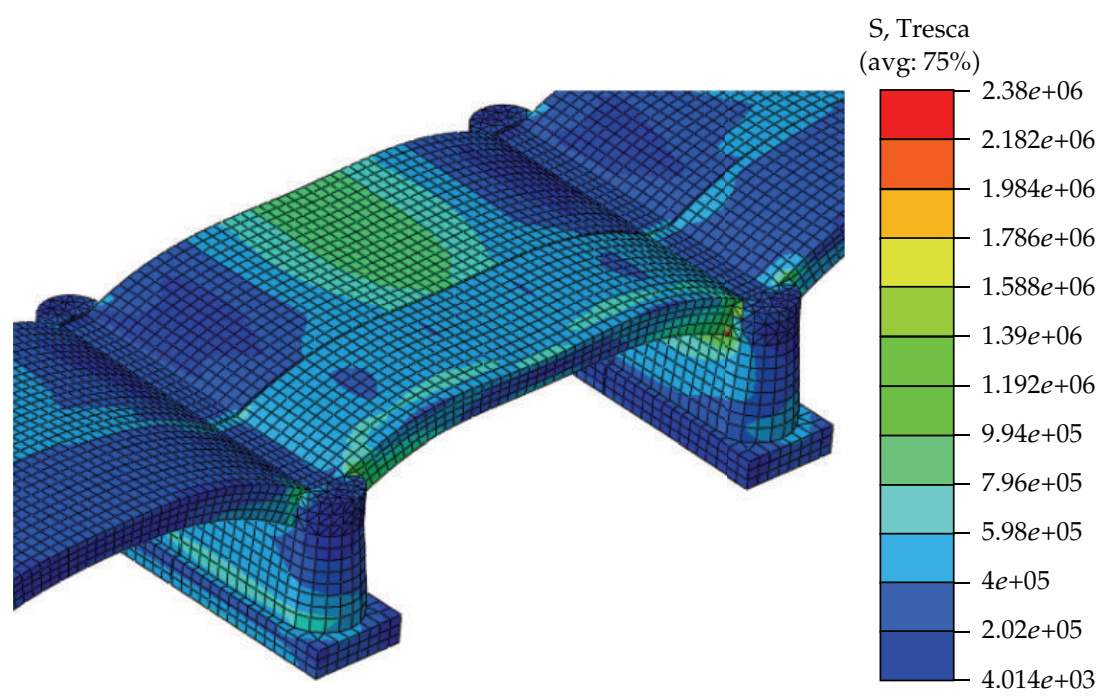

Figure 18: Resulting Tresca stress due to the load case SW/2-4 applied considering the structural strengthening of the bridge.

the load case SW /2-4, Figures 17 and 18 show the maps of the Tresca stress on the 4th span for the bridge in its actual state and in the hypothesis of the structural strengthening, respectively. Stress maps are obtained by means of standard shape functions, but values in Table 3 have been collected using the quilt visualization (one average value per element) in order to avoid the nonrealistic stress peaks that, in a displacement-based finite element model, characterize the stress distribution obtained via the elastokinematic relationship. A better evaluation of the stress distribution could be obtained by employing advanced postprocessing techniques $[20,21]$. As it can be noted, in the actual state the stress level is quite low and far from the maximum strength of the masonry. Accordingly, the hypothesis of linear material behaviour done in setting up the finite element model can be considered reliable. Moreover, the low 
Table 3: Maximum values of the stresses in the actual state and after the structural strengthening (MPa).

\begin{tabular}{lcccccc}
\hline \multirow{2}{*}{ Load case } & \multicolumn{3}{c}{$\begin{array}{c}\text { Actual state } \\
\text { Tresca }\end{array}$} & \multicolumn{2}{c}{ Min Principal } & \multicolumn{3}{c}{$\begin{array}{c}\text { After strengthening } \\
\text { Max }\end{array}$} & Tresca & Min Principal Max \\
\hline SW $/ 2-1$ & 1.81 & -2.02 & 0.45 & 1.65 & -1.85 & 0.50 \\
SW $/ 2-2$ & 2.62 & -2.93 & 0.54 & 2.00 & -2.24 & 0.65 \\
SW $/ 2-3$ & 2.95 & -3.31 & 0.61 & 2.32 & -2.60 & 0.80 \\
SW $/ 2-4$ & 3.00 & -3.35 & 0.54 & 2.39 & -2.69 & 0.79 \\
\hline
\end{tabular}

stress level indicates the absence of specific structural health alerts concerning the actual state of the bridge. Comparing the results of the actual state and after the strengthening intervention it is possible to observe that, as could be expected, the consolidation intervention engenders a lowering of the stress level. In particular, an average lowering of about $20 \%$ is obtained. In the presence of cyclic actions, like those due to the passages of the trains, this lowering of the stresses could have beneficial effects on the long-term structural health of the bridge [22].

\section{Conclusions}

The structural health assessment of the fifteen-span railway masonry arch bridge spanning over the Reno river in the city of Bologna Italy by finite element modelling and experimental testing has been presented. In particular, the finite element model has been tuned using the results of an experimental campaign involving static and dynamic load tests performed on the structure accompanied by some material testing performed on portions of masonry taken from the bridge. A part of the outcomes of the experimental campaign have been used to calibrate the finite element model and a part to validate it. A very good agreement between numerical and experimental results has been obtained, so confirming the underlying assumptions made in setting up the finite element model. Then, the finite element mode has been used to evaluate the structural health of the bridge both in its actual state and in the hypothesis of a structural consolidation intervention. In all, the paper shows that the combination of experimental and numerical results is essential to reach a good level of knowledge when dealing with this kind of structures. Further developments regard the introduction of material nonlinearities in the finite element model, in order to evaluate the structural behavior also when ultimate limit state conditions occur. In this case, also seismic vulnerability analysis could be performed and a complete safety assessment developed.

\section{References}

[1] A. Brencich and D. Sabia, "Experimental identification of a multi-span masonry bridge: the Tanaro Bridge," Construction and Building Materials, vol. 22, no. 10, pp. 2087-2099, 2008.

[2] A. Brencich and U. De Francesco, "Assessment of multispan masonry arch bridges-I: simplified approach," Journal of Bridge Engineering, vol. 9, no. 6, pp. 582-590, 2004.

[3] D. M. Armstrong, A. Sibbald, C. A. Fairfield, and M. C. Forde, "Modal analysis for masonry arch bridge spandrell wall separation identification," NDT and E International, vol. 28, no. 6, pp. 377-386, 1995.

[4] C. Melbourne, T. G. Hughes, M. J. Blackler, and M. Gilbert, "A review of the UK masonry arch assessment methods. discussion," Proceedings of the ICE, vol. 134, no. 3, pp. 287-289, 1999.

[5] A. Thavalingam, N. Bicanic, J. I. Robinson, and D. A. Ponniah, "Computational framework for discontinuous modelling of masonry arch bridges," Computers and Structures, vol. 79, no. 19, pp. 1821-1830, 2001. 
[6] C. Mazzotti, S. deMiranda, G. Castellazzi, and F. Carrea, "Structural assessment of the railway masonry arch bridge crossing the Reno river in Bologna," in Proceedings of the 6th International Conference on Bridge Maintenance, Safety and Management,, pp. 1078-1085, 2012.

[7] P. J. Fanning and T. E. Boothby, "Three-dimensional modelling and full-scale testing of stone arch bridges," Computers and Structures, vol. 79, no. 29-30, pp. 2645-2662, 2001.

[8] P. J. Fanning, L. Sobczak, T. E. Boothby, and V. Salomoni, "Load testing and model simulations for a stone arch bridge," Bridge Structures, vol. 1, no. 4, pp. 367-378, 2005.

[9] A. Bayraktar, A. C. Altuniik, F. Birinci, B. Sevim, and T. Türker, "Finite-element analysis and vibration testing of a two-span masonry arch bridge," Journal of Performance of Constructed Facilities, vol. 24, no. 1, pp. 46-52, 2010.

[10] B. Sevim, A. Bayraktar, A. C. Altuniik, S. Atamtürktür, and F. Birinci, "Finite element model calibration effects on the earthquake response of masonry arch bridges," Finite Elements in Analysis and Design, vol. 47, no. 7, pp. 621-634, 2011.

[11] Hibbitt Inc., Abaqus Theory Manual, Karlsson \& Sorensen, 1998.

[12] G. Castellazzi, "On the performances of parametric finite elements when geometry distortions occur," Finite Elements in Analysis and Design, vol. 47, no. 12, pp. 1306-1314.

[13] R. J. Allemang and D. L. Brown, "A unified matrix polynomial approach to modal identification," Journal of Sound and Vibration, vol. 211, no. 3, pp. 301-318, 1998.

[14] D. J. Ewins, Modal Testing: Theory, Practice and Application, Wiley, 2nd edition, 2001.

[15] E. Sassoni and C. Mazzotti, "The use of small diameter cores for assessing the compressive strength of clay brick masonries," Journal of Cultural Heritage. In press.

[16] Eurocode 6, "Part 1-1, General Rules for reinforced and unreinforced masonry, including lateral loading," 2009.

[17] C. Gentilini, L. Govoni, S. de Miranda, and G. Gottardi, "Three-dimensional numerical modelling of falling rock protection barriers," Computers and Geotechnics, vol. 44, pp. 58-72, 2012.

[18] L. Govoni, S. de Miranda, C. Gentilini, G. Gottardi, and F. Ubertini, "Modelling of falling rock protection barriers," International Journal of Physical Modelling in Geotechnics, vol. 11, pp. 126-137, 2011.

[19] NTC 2008, “Norme Tecniche per le Costruzioni,” D.M. 14/01/08, 2008.

[20] G. Castellazzi, S. de Miranda, and F. Ubertini, "Adaptivity based on the recovery by compatibility in patches," Finite Elements in Analysis and Design, vol. 46, no. 5, pp. 379-390, 2010.

[21] S. de Miranda, L. Patruno, and F. Ubertini, "Transverse stress profiles reconstruction for finite element analysis of laminated plates," Composite Structures, vol. 94, no. 9, pp. 2706-2715, 2012.

[22] C. Carloni, K. V. Subramaniam, M. Savoia, and C. Mazzotti, "Experimental determination of FRPconcrete cohesive interface properties under fatigue loading," Composite Structures, vol. 94, no. 4, pp. 1288-1296, 2012. 


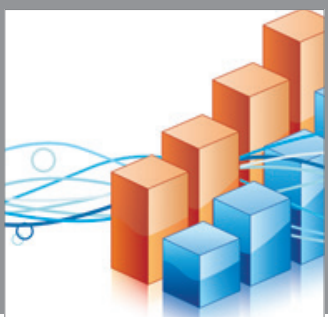

Advances in

Operations Research

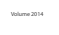

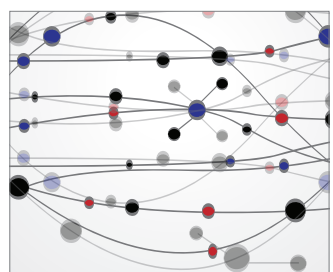

\section{The Scientific} World Journal
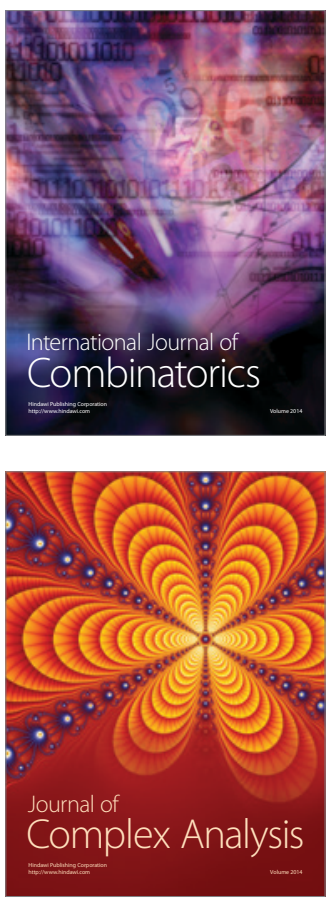

International Journal of

Mathematics and

Mathematical

Sciences
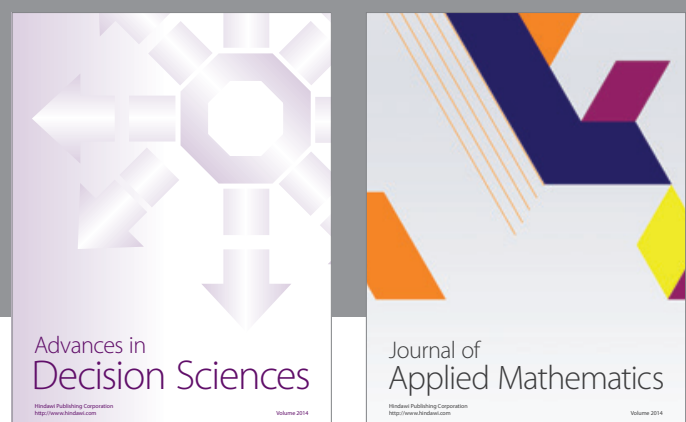

Journal of

Applied Mathematics
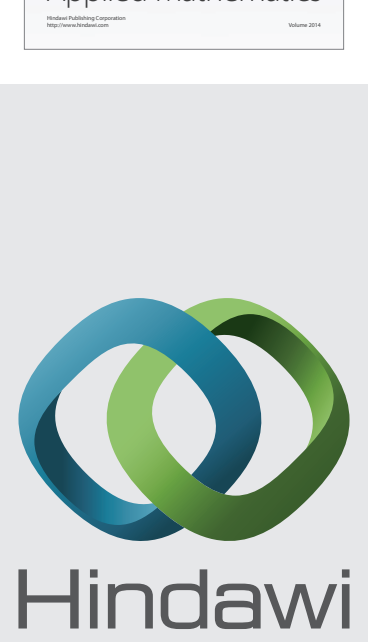

Submit your manuscripts at http://www.hindawi.com
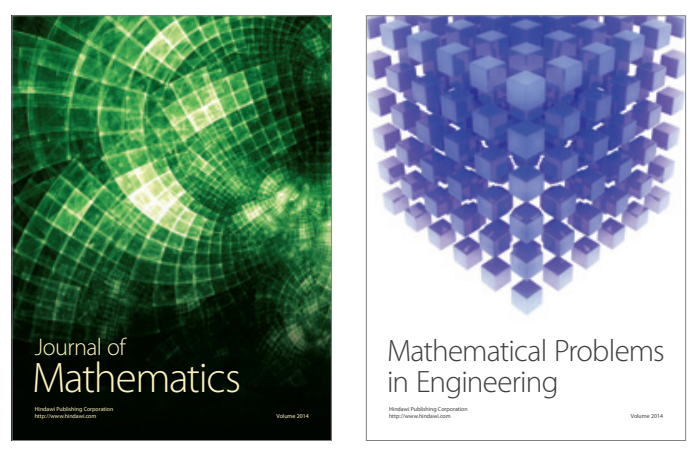

Mathematical Problems in Engineering
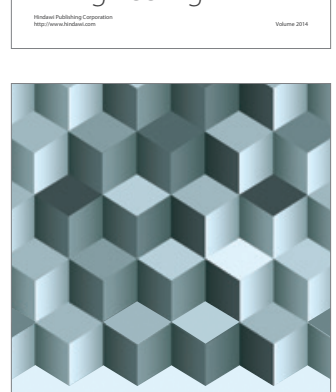

Journal of

Function Spaces
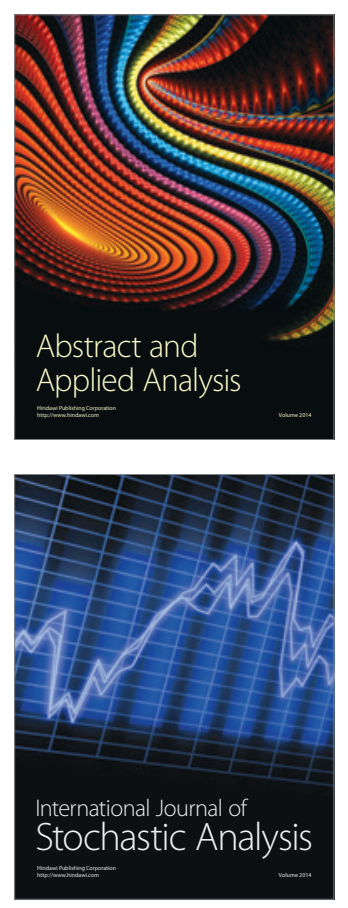

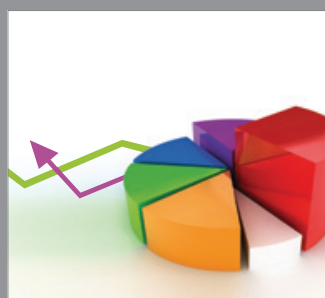

ournal of

Probability and Statistics

Promensencen
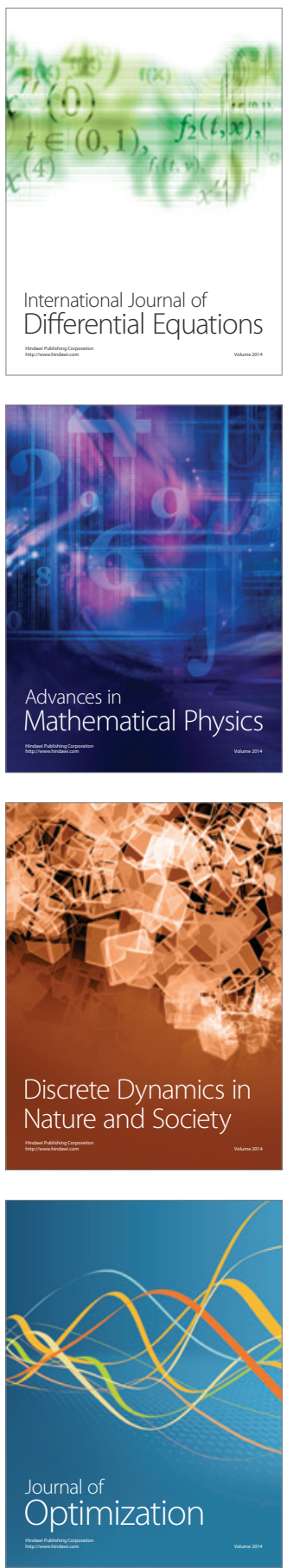